\title{
Behavioural indicators of translators' decisional styles in a translation task: A longitudinal study
}

\author{
Olha Lehka-Paul \\ Adam Mickiewicz University, Poznań \\ olehka@wa.amu.edu.pl
}

\begin{abstract}
Translation Process Research defines translation as a decision-making process, but a plethora of studies has demonstrated that there is high individual variation in the translators' styles of making decisions. The present interdisciplinary empirical study combines the theory of personality types and translation process research in order to identify the behavioural indicators that characterise translators' decisional styles at the stage of end revision, where final decision-making takes place. As based on previous research, such indicators as the duration of end revision, pause length and number, the number of deleted characters and the types of corrections introduced at the stage of end revision may comprise the behavioural variables that define the translators' styles of decision-making. The analysis of the data shows that two distinct behavioural styles may be distinguished, and their nature lies in the translators' individual preferences for one of the two dichotomous psychological functions responsible for decision-making.
\end{abstract}

Keywords: Translation process research; decision-making; translator styles; selfrevision; psychological functions.

\section{Introduction}

With the arrival of new machine translation technologies and the overall higher levels of self-reported knowledge of foreign languages in the modern society, ${ }^{1}$ a need has appeared to update and improve translation training curricula, as well as to standardise the formal requirements to young translators

\footnotetext{
${ }^{1}$ According to Eurostat data as of $2016,80 \%$ of the adult working-age population reported that they knew at least one foreign language (https://ec.europa.eu/eurostat/statistics-explained/ index.php/Foreign_language_skills_statistics\#Number_of_foreign_languages_known) (date of access: 1 Dec. 2019).
} 
entering the translation market. According to the presently effective European Master's for Translation (further referred to as "EMT") competence framework issued in 2017, the universities that train future translators need to ensure that the graduates acquire five basic competences that are essential for being successful in the current translation market. Among these competences is the "language and culture" competence described as "the driving force behind all the other competences" (EMT competence framework 2017: 6), which entails extensive knowledge of both working languages and cultural backgrounds. The core of the framework, however, constitutes the "translation" competence that consists in a complex set of "strategic, methodological and thematic competences" (EMT competence framework 2017: 6), whose main practical skills include being able to analyse the source document, implement adequate translation strategies, conduct revision and quality control, and use the translation tools relevant for the task at hand. Thus, the "translation competence" can be understood in the broadest sense as the translator's ability to make the necessary decisions during the whole process of translation - from receiving the task to delivering the target text to the client - and being able to justify those decisions.

The importance of the decision-making skills within the "strategic competence" has also been acknowledged in empirical research projects into translation competence development and acquisition, such as PACTE (e.g. Hurtado Albir 2017) and TransComp (Göpferich \& Jääskeläinen 2009). Hence, translators are expected to be highly proficient bilinguals whose key competences and skills lie in efficient decision-making and quality control.

Empirical research into the translation process has shown, however, that translators display different behaviours in the translation process, and therefore adopt different decision-making styles. For example, some translators tend to generate a lot of "intermediate solutions" (a term coined by Toury 1995: 218) as temporary translation variants in the process of drafting the translation, while others prefer leaving most of the decision-making for the end revision stage, i.e. once the first draft has been finished. Some translators tend to display a lot of "backtracking" behaviour (Carl et al. 2011), which means returning to the previously typed translation chunks in order to revise them, while others have a tendency to revise their initial decisions once the whole text has been translated and a more "global" perspective of the translated text has been made available (Dragsted \& Carl 2013). Despite the fact that translation researchers generally acknowledge the existence of different translation behaviours as individual "idiosyncratic regularities" (Munõz Mar- 
tín 2014: 59), there has hardly been any attempt to find and explain the potential sources of such differences.

Providing potential explanations for the individual differences in people's behaviours is one of the tasks of personality psychology. Jung ([1921] 1971) believed that people display different behaviours due to their individual preferences to use certain psychological functions responsible for information processing (the functions of Intuition and Sensing), and decisionmaking (the functions of Feeling and Thinking). Myers-Briggs Type Indicator (further referred to as "MBTI"), a psychometric tool based on Jung's ([1921] 1971) theory of psychological types, has been efficiently used to identify people's preferred psychological functions so as to explain and predict their potential behaviours (Higgs 2001; Furnham et al. 2008; SchwedaNicholson 2005; Hubscher Davidson 2009), whose results will be discussed further in the article.

The present sample study looks into the potential relationship between the differences in the decision-making styles displayed by a sample of translation students and professional translators, and their different preferences for a dominant decision-making function (Thinking or Feeling). The study also seeks to explore whether the potential role of the preferred decision-making function remains stable or changes as translation competence develops. Thus, it is an innovative and interdisciplinary attempt to investigate the nature of translator's decision-making in a longitudinal design.

\section{The role of psychological functions in predicting behaviour}

MBTI, one of the most popular psychometric tests widely used in personality psychology and career counselling, dates back as far as 1921, when Jung published his views on personality types. According to Jung ([1921] 1971), personality types are formed on the basis of people's preference to certain psychological functions related to each of the two major dichotomies - information processing and decision-making. The former dichotomy is composed of the functions of Intuition, which involves relying on the unconscious perception of information, and Sensing, which means relying on physical senses while processing information. The decision-making dichotomy comprises the Thinking function, which involves making decisions based on rational ideas, facts and logics, and the Feeling function that means arriving at decisions on the basis of subjective evaluation of a given situation. Jung 
([1921] 1971) believed that people's behaviour depends on their preference to one of the functions in each dichotomy. He also claimed that people tend to choose one of the two types of attitudes or orientations - extraversion or introversion. Those with the former attitude are more open in their relationships with the world, and those with the latter tend to be more reserved and introspective. Myers-Briggs (1962) adapted Jung's ([1921] 1971) theory of personality types and composed a personality test that has since then received worldwide acclaim.

Due to the relative ease of its administration and interpretation of results, MBTI has become a practical tool eagerly applied in business and industrial settings in order to test the predispositions and predict the behaviours of potential employees. Several studies in the area of industrial and occupational psychology discovered that managers and people in various leadership positions more often showed preference for the Thinking rather than Feeling function in the decision-making dichotomy (Gardner \& Martinko 1996; Higgs 2001; Furnham et al. 2008), which was accounted for by the fact that those with the Thinking function preference tend to opt for more logical and factual solutions than those with the Feeling function preference. The Feeling function was associated with high anxiety levels (Furnham et al. 2008) among employees whose leadership skills were rated lower as opposed to those who showed preference for the Thinking function. In a different study conducted on a sample of medical students, Stilwell et al. (2000) found that those students whose decision-related dominant function was Feeling more often chose such specialities as family medicine or primary care. The medical students with the Thinking function preference more often opted for surgical specialities.

The above observations may hint at the idea that whenever a fast and logical (as in the case of surgeons and managers) decision-making is involved, it is the Thinking function preference that is dominant, as opposed to the use of the Feeling function in the situation when slower and more valuesoriented (as in the case of family doctors) decision-making is required. These observations might justify Schweda-Nicholson's (2005) and Hubscher Davidson's (2009) exploratory ideas about the role of the decision-making functions in translators' and interpreters' professional lives. In a study on 68 interpreting trainees, Schweda-Nicholson (2005) found that most of her students showed preference for the Thinking $(N=4)$ rather than Feeling function $(N=24)$. On the other hand, Hubscher Davidson (2009) reported that out of 20 participants in her study, 13 expressed their preference for the Feel- 
ing function as opposed to 7 participants with the preference for the Thinking function. Schweda-Nicholson (2005: 125) suggested that the general Thinking function preference among interpreters, and hence the Feeling function preference among translators, might be related to the differences in the nature of decision-making in interpreting and translation, which is relatively quick and logical in the former (as manifested by the Thinking function preference) and comparatively slow and contemplative in the latter (as manifested by the Feeling function preference).

Since the present study focuses on the translators' decision-making styles, the Thinking and Feeling functions dichotomy will be considered at the data analysis stage. Thus, all participants of the study will be divided into the "Feeling types" and "Thinking types" according to their preference to one of the two functions, as revealed by the MBTI testing. The test itself will be explained and discussed in more detail in the section devoted to the tools and materials used in the study.

\section{Translation styles and relevant behavioural indicators}

The topic of translation styles, i.e. the individual ways in which translators behave in the translation process ("individual working styles", Jakobsen 2003: 82), has become popular since research into the behavioural aspects of the translation process arrived in the discipline, with methodology ranging from think-aloud protocols and eye-tracking (borrowed from cognitive psychology) to screen-recording and key-logging (borrowed from writing process research). Among the indicators used to identify different translation styles have been the duration of translation process stages, i.e. orientation, drafting and end-revision (Jakobsen 2003; Carl et al. 2011), the number and duration of eye fixations (Carl et al. 2011; Dragsted and Carl 2013), the number of characters deleted at the stages of drafting and end revision (Asadi \& Séguinot 2005; Mossop 2007; Alves \& Vale 2011; Dragsted \& Carl 2013; Hansen 2013) and the types of revisions performed at the two translation stages (Englund Dimitrova 2005; Antunović \& Pavlović 2011). It has also been observed that pause length and frequency are another two features of individual variation in translation process behaviours (Dragsted 2005; Dragsted 2012; O’Brien 2006).

In his seminal study comparing the efficiency of the methods of thinkaloud protocols and key-logging, Jakobsen (2003) found that the number of 
"revision keystrokes" per 100 keys logged (calculated as the total number of deleted characters divided by the total number of characters types and multiplied by 100, Jakobsen 2003: 82) was the only behavioural characteristics that remained unaffected by the experimental method (think-aloud or keylogging). This observation allowed Jakobsen (2003) to suggest that translators display their "individual working styles" when it comes to the amount of self-revision performed. In his previous study, Jakobsen (2002) noticed that there is a difference between the amount of self-revision done by students and professional translators, with the stage of end revision (the part of the translation process that starts when the first draft has been finished and continues till the final key in the task is pressed, Jakobsen 2002) being longer in the group of professional translators with fewer revisions introduced at this stage than in the group of translation students. Conversely, Schaeffer et al. (2019) in their study on the relationship between translators' self-revision behaviour and efficiency, which was defined as the total time spent by a translator on a given translation assignment (Schaeffer et al. 2019: 228), found no effects of expertise level on translators' efficiency scores. As regards the distribution of the stages of the translation process, Schaeffer et al. (2019: 235) found that the more deletions were introduced at the drafting stage, the less need there was for a longer stage of end revision. Interestingly, Schaeffer et al. (2019) concluded that irrespective of the participants' expertise level, a more efficient (i.e. quicker) translation process is characterised by more extensive concurrent source text reading and target text production and fewer deletions during the stage of producing the initial translation draft (Schaeffer et al. 2019: 240). However, as the authors themselves admit (Schaeffer et al. 2019: 239), the results regarding the lack of the effects of expertise level might have been influenced by the lack of such important data as the years of formal translation training and professional translator experience. In addition, it should be noted that the analysis was conducted on a sample of 164 participants who translated into six languages belonging to different language families (Spanish, Japanese, Danish, Hindi, Chinese and German, Schaeffer et al. 2019: 230). Hence, the variable of language relatedness might potentially influence the distribution of the stages of the translation process and the degree of self-revision performed, as well as the efficiency scores.

Dragsted (2005) in her study into the translator's cognitive styles, found that both translation trainees and professional translators prefer the analytic processing style, characterised by lower production speed, longer pauses and 
processing at word/phrase level (Dragsted 2005: 66) while dealing with a demanding translation task. However, in the case of easy texts professional translators tend to use the integrated processing style, characterised by higher production speed, shorter pauses and processing at clause/sentence level (Dragsted 2005: 66). Notably, Dragsted (2005) found that the stage of the translation process that was most subject to individual variation in both groups of participants was the stage of end revision.

The potential effect of the expertise level was also found by Carl et al. (2011) who observed that professional translators are more prone to substantial end revision stage (with $20 \%$ of the total task time spent on end revision) than translation students, who tend to perform most of the text revision during the drafting stage, i.e. their behaviour is characterised by "online revision". On the contrary, Dragsted \& Carl (2013) found no clear expertise effect in their study into translation styles. However, behavioural data did point to two major styles: "global", defined by longer orientation stage, eye fixations at sentence level, and the preference for end revision (Dragsted \& Carl 2013: 149), and "local" style defined by shorter orientation stage, eye fixations at word/phrase level and the preference for online revision. Similar behavioural patterns were identified by Asadi \& Séguinot (2005) in their analysis of the translation processes of nine professional translators. The researchers proposed the terms "prospective thinking" and "translating on-screen" to refer to similar characteristics as those attached to Dragsted's (2005) "global" and "local" translation styles respectively. In addition, Asadi and Séguinot (2005) agreed with Engund Dimitrova (2005) concerning the suggestion that introducing most of the revisions online (at the drafting stage) possibly allows translators to reduce cognitive load and type faster, but the choice whether to do so depends largely on the individual translator (Asadi \& Séguinot 2005: 530). In a similar fashion, Dragsted (2012) suggested that some translators tend to make longer pauses and eye fixations while reviewing different translation solutions in their mind, "the problem space" (Dragsted 2012: 95) without actually typing them, whereas others prefer shorter pauses and fixations, as well as more intermediate solutions typed and immediately modified. A similar observation goes back to Krings ([1995] 2001: 530) who differentiated between "correctional" and "anticipatory planners", the former having a tendency to immediately revise their initial translation solutions, and the latter being more prone to leaving most of the revision for the end revision stage. 
Mossop (2007: 19) claimed that the translator's "individual psychology" might potentially be the source of the variations displayed in the number and type of revisions performed in translation. Hansen (2013: 62), in her longitudinal study into the translator's individual styles, arrived at a similar conclusion concerning the potential influence of the translator's personality on his or her styles of behaviour in the translation process. Moreover, when testing her translation students after ten years of working in the translation market, Hansen (2013) observed that there was no effect of the level of expertise and amount of experience on the translator's style of behaviour as regards selfrevision.

Englund Dimitrova (2005: 113) proposed a qualitative and typological analysis of the translators' decision-making in translation. As regards the drafting stage, both students and professional translators introduced mostly lexical and syntactic types of modifications, with professional translators outnumbering students in terms of the syntactic ones. At the stage of end revision, the professional translators mostly focused on content-related revisions of their initial decisions, whereas students on the syntactic ones. Similarly, Antunović \& Pavlović (2011: 231) in their research into the effects of directionality on the translators' behaviours in the translation process found that lexical and syntactic types of revisions were the most numerous, with similar patterns of distribution across the stages of translation in both conditions (from L2 into L1, and from L1 into L2).

The above discussion of the findings of empirical research into translation styles points to the important role of the translators' self-revision behaviour, especially at the stage of end revision (Jakobsen 2003; Dragsted 2005). This observation is in line with research into the writing process, where selfrevision is regarded as the main "decisional activity that is controlled at a metacognitive level" (Piolat 1990: 186 as translated by and quoted from Alamargot \& Chanquoy 2001: 110). The stage of end revision in translation is characterised by high individual self-monitoring and quality control, and aims at perfecting the target text and arriving at final decisions. However, it remains unclear why translators behave differently while end-revising their translations - some tend to skip end revision or keep it as short as possible, whereas others prefer spending a lot of time end-revising their texts and introducing a lot of changes at this stage of the translation process. Referring to Jung's ([1921] 1971) dichotomy of decision-related psychological functions that may potentially account for different decision-making behaviours, the present study will concentrate on exploring the relationship between the 
translators' "individual psychology" (Mossop 2007) and the behavioural indicators of decisional styles as manifested in self-revision activities at the stage of end revision in a translation task. Moreover, the study seeks to test whether the same behavioural indicators of psychologically rooted decision styles will be retained irrespective of the text type and translators' expertise level.

\section{Hypotheses}

Previous research into the behavioural aspects of the translator's working styles has shown that such indicators related to the stage of end revision in translation as its duration, the duration and length of pauses, the number of deleted characters and the types of corrections introduced might be potentially influenced by the translator's individual psychological predispositions. According to Jung ([1921] 1971), the dichotomy of the Thinking and Feeling functions is responsible for decision-making behaviours. Thus, the first hypothesis reads as follows:

(1) The preferred decision-making function (Thinking or Feeling) will influence such behavioural characteristics in the translation process as end revision time, the number and length of pauses made at the stage of end revision, the number of characters deleted at this stage, and the type of corrections made at the end revision stage.

The second hypothesis seeks to tap into Hansen's (2013) claim about the stability of behavioural patterns and the impact of the translator's preferred psychological function as translation competence grows:

(2) Preferred decision-making functions will retain their influence on decision-related behavioural characteristics in the translation process as translation competence develops.

Finally, the third hypothesis aims to put to the test the equivocal findings of previous studies (e.g. Jakobsen 2003 versus Dragsted \& Carl 2013) regarding the differences and similarities between the behaviours of translation students and professional translators. In particular, it will be tested whether the professional translators indeed prefer having a more extensive end revision 
stage as opposed to translation students, or it is the influence of the psychological predispositions that can explain the differences in the translators' and students' behaviours.

(3) Preferred decision-making functions will be observable in the translators' decision behaviour in the translation process irrespective of expertise level

Hence, the three hypotheses will help to explore whether the translators' psychological predispositions may account for the individual variations in the selected temporal, quantitative and qualitative indicators of the translators' behaviour in the process of translation, and whether their role will remain the same at different levels of translation competence and expertise development.

\subsection{Selected behavioural indicators}

As based on the overview of research into translation styles, the following behavioural indicators have been considered for analysis:

(1) the duration of end revision stage,

(2) the duration of all pauses made at the end revision stage,

(3) the number of all pauses made at the end revision stage,

(4) the number of characters deleted at the end revision stage,

(5) the types of corrections introduced at the end revision stage.

Variable (1), the duration of end revision stage, has previously been found to be particularly subject to individual variations (Jakobsen 2003; Dragsted 2005; Dragsted \& Carl 2013). Thus, the analysis of the data will help verify whether the preferred psychological function may potentially be the reason for such variations. The indicators of the duration (2) and number of pauses made at the end revision stage (3) will point to the duration and distribution of "mental editing" (Mossop 1982) in relation to the translators' preferred psychological function. Thus, variables (1) to (3) can be referred to as temporal indicators of translators' decisional styles. The number of deleted characters (4) will reveal the amount of self-revision done by participants while revising their initial decisions at the end revision stage, and may therefore be 
considered as a quantitative indicator of decisional styles. Previous studies have shown that translators tend to perform different amount of self-revision in terms of this indicator, i.e. some prefer deleting more at the end revision stage than others (Mossop 2007; Carl et al. 2011; Dragsted \& Carl 2013). The (5) analysis of the types of corrections introduced will account for the qualitative characteristics of translators' decision styles.

As regards the types of corrections, the present study will differentiate between two types - "surface" and "deep" corrections (Lehka-Paul 2018). The former type includes the revisions of typos, orthographical mistakes, punctuation and other minor changes, i.e. all kinds of form-related corrections that do not interfere with the meaning and style of the target text. The latter type refers to the lexical, syntactic and stylistic changes, i.e. those that modify the meaning and style of the target text. The terms "surface" and "deep" corrections have been adopted from writing process research (Chanquoy 1997), and allow making a rather basic distinction between the types of revisions that translators make in the process of translation, which is sufficiently informative for the aims of the present study.

\section{Description of the study}

The presently reported sample study was conducted within the framework of my $\mathrm{PhD}$ project. As the study is characterised by a longitudinal design, the materials were gathered during two consecutive academic years (2014/2015, 2015/2016), and further subject to quantitative and qualitative analysis. Detailed descriptions of the samples of participants, the tools and methods used in the study, the experimental procedure, selected behavioural indicators and hypotheses are provided in the following sections of the article.

\subsection{Experimental procedure}

The study was conducted in the Language and Communication Laboratory at the Faculty of English, Adam Mickiewicz University in Poznań, Poland. All participants were invited to translate two texts representing different text types (Reiss [1971] 2000), expressive and informative, from English into Polish. To ensure that the order of the texts did not influence the participants' translation performance, it was counterbalanced, i.e. one participant started 
with an expressive text, the other participant with an informative text. Due to the longitudinal design of the study, the order of the texts in both rounds was different for the same participant. As the data were collected from participants at the end of their first and then their second year of the Master's programme, the additional question that appeared in the self-report questionnaires in the second year was whether they remembered their translation solutions from the previous year. All students who took part in both rounds of the experiment stated that due to a wide range of practical translation assignments that they had had during the previous year it was impossible for them to remember translating two short texts a year before.

The participants were not pressed for time, and could use any reference materials they could find available on the Internet. Importantly, before the experiment all participants were instructed not to use the Eur-Lex website due to the possibility to find the Polish version of the Treaty on the website. Each participant's history of Internet search was then carefully scrutinised and no violations of this instruction were recorded.

The participants were asked to translate the texts in a way that would satisfy their own individual translation quality standards. This part of the brief was dictated by the aims of the PhD project. The students' motivation to perform well in the study was boosted by giving them additional points for participation in research experiments towards their final mark for one of their translation classes. After translating the texts, the participants were asked to complete the MBTI test. Then the participants were asked to fill out a selfreport questionnaire, which was meant to collect such information as the participants' age, the duration of translation experience, as well as other data which were later used for the main $\mathrm{PhD}$ study, and go beyond the scope of the analysis presented in this article.

\subsection{Participants}

The data analysed in the present study were collected from a sample of seven 1MA translation students (Mage $=22.7, S D=0.5$ ) obtaining their degree at the Faculty of English, Adam Mickiewicz University in Poznań, Poland, and a sample of seven professional translators (Mage $=35, S D=6.3$ ). The seven translation students participated in the experiment twice - the first round took place at the end of their first year of the Master's programme in translation $(2014 / 2015)$, and the second round was conducted at the end of the sec- 
ond year (2015/2016). It should be noted, though, that during the first round there were ten participants who took part in the study, but only seven of them agreed to participate again the following year. Thus, the number of participants in the present longitudinal study was dictated by the number of students who took part in the experiment during both rounds.

The students had received an average of seven months of formal training in written translation by the time of the first round of the experiment, and an average of seventeen months by the time the second round was conducted. The students' working languages were Polish (L1) and English (L2). Their level of proficiency in English was not tested in the course of the experiment, as a language proficiency test constitutes one of the elements of the recruitment process for the MA programme in translation at Adam Mickiewicz University, with the level expected from candidates being $\mathrm{C} 1$ (in line with the EMT competence framework mentioned above).

The results of the students' MBTI tests showed that three of them displayed preference towards the Feeling function, and four of them towards the Thinking function in their decision-making processes. Importantly, the same MBTI results for the Thinking-Feeling dichotomy were recorded during both rounds of the study for the same participants, which points to the potential consistency of the decision-making preferences reported by the students.

The professional translators considered in the present analysis were selected from the pool of 17 professional translators (Mage $=37, S D=8.1$ ) who took part in the main $\mathrm{PhD}$ study. All professional translators had at least three years of experience in providing translation services (Mexperience $=13$ years, $S D=8.6$ ). Similar to translation students, all professional translators had Polish as their native language (L1), and English as their foreign language (L2). The criterion for selecting the professional translators for the present analysis was based on the number of translation students who took part in both rounds of the study. Having the same number of participants in both samples aimed to ensure the comparability of the data. Similarly, as there were four Thinking types and three Feeling types among translation students, the aim was to randomly select the same number of Thinking and Feeling type professionals. Thus, the set.seed command in the $\mathrm{R}$ statistical environment was used to select the respective numbers of both types of professional translators. It should be noted that such a small number of participants limits the possibility of generalising the results of the present sample study for a larger population, and so the data should be treated with caution and regarded as an invitation for further empirical research into the relation- 
ship between the psychological aspects of translators' personality and their decision-making styles.

\subsection{Tools, methods and materials}

The behavioural data from the translation process were collected with the help of Translog-II (Carl 2012), a key-logging programme that enables recording the process of translation as it happens in real time by means of registering all keyboard and mouse activities. The analysis of Translog files allows the researcher to obtain such behavioural data as total translation task time, the number of production units and user events, and the number of characters deleted by a participant. Depending on the aims of the study, it is also possible to select certain areas of interest in a given translation task and run separate analyses. The function was important for the purposes of the presently reported study, as the data from the end revision stage of the participants' translation processes were included in the analyses. The top-tobottom layout of source and target text appearance was selected, so that the source text was given in the upper part of the Translog window, and the target text was supposed to be typed in the lower part of the window.

The participants' preferred psychological functions were determined by means of the online version of the Myers-Briggs Type Indicator available at www.humanmetrics.com. This version of the test had been used in previous research into the psychological aspects of the translator's personality (Schweda-Nicholson 2005; Hubscher Davidson 2009). The online version consists of 64 statements (e.g., "When making a decision, you rely more on your feelings than on analysis of the situation") with five answers on a Likert-scale ranging from strong "yes" to strong "no". As based on the experimenter's observations, it took the participants on average ten minutes to complete the test.

As regards the materials used for the study, two texts representing two different types according to Reiss's functional text typology were selected and initially tested in a sample study (Lehka-Paul \& Whyatt 2016). The expressive text type was an excerpt from W. S. Maugham's short story "Gigolo and Gigolette" (Maugham 1988), and the informative text was a fragment of an article in the former version of the Treaty of the European Union as of 2012. Both texts were of similar length (c. 250 words). The use of the two texts was supposed to show whether the translator's behaviours changed or 
remained the same depending on the type of the translation task - the one that demanded a more creative approach (as in the case of an expressive text), or the one that required the knowledge and use of certain grammatical constructions and terminology typical of legal documents (as in the case of an informative text). The next section will focus on the description and discussion of results of the present longitudinal sample study.

\section{Results and discussion}

The potential effect of the translators' preferred decision-making function on the selected behavioural indicators of the translators' decisional styles will be presented and discussed with references to each of the three hypotheses above. In order to better illustrate the role of the psychological functions, the overall group results for each of the selected variables will be shown first, and then the data will be divided according to the participants' preferred psychological function and analysed accordingly.

As regards the total duration of the translation task, it took 1MA translation students on average 37 minutes to translate the expressive text $(M=$ $37.2, S D=10.9)$, and on average 30 minutes to translate the informative text $(M=30.4, S D=11.6)$. The following year it took the same students an average of 25 minutes to deal with the expressive text $(M=24.5, S D=5.9)$, and an average of 23 minutes - with an informative text $(M=23.2, S D=3.9)$. The professional translators needed on average 40 minutes to translate the expressive text $(M=40.9, S D=12.1)$, and 28 minutes to translate the informative text $(M=27.6, S D=5.9)$.

The Translog file of each participant was further analysed and the total task time was divided into three stages of the translation process (Jakobsen 2002): orientation (from the opening of the Translog file till the first key has been pressed), drafting (from the moment the first key has been pressed till the first full draft has been finished), and end revision (since the first draft has been finished till the closing of the Translog file). The duration of each stage was then calculated in percentage in order to better illustrate the time that has been spent on each of the stages in relation to the total duration of each of the translation tasks (expressive and informative texts). Due to the aims of the presently reported study, the duration of the end revision stage will be considered for further analysis and discussion. 
Figure 1 shows the mean end revision time as percentages in the three groups of participants - the seven 1MA translation students, the same students in their second year of the Master's programme (2MA students in the Figure), and the seven professional translators (marked as "PRO" in the Figure). The abbreviations "EXP" and "INF" stand for the text type - expressive and informative - in this and all other figures shown further in the section.

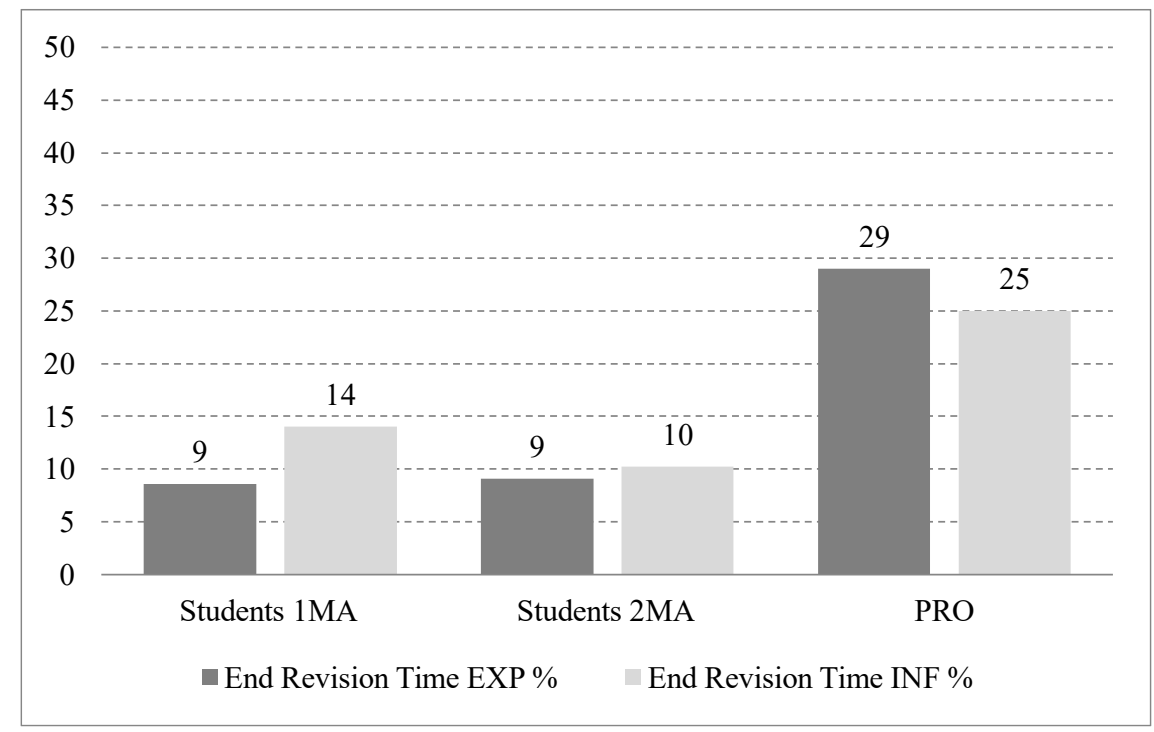

Fig. 1. Mean duration of end revision stage as percentage: all participants, both texts.

The professional translators spent much more time end-revising both texts than the students in their first and second years. This observation is similar to the one made by Jakobsen (2003) and Carl et al. (2011). The students in their second year spent less time end-revising the informative text than in their first year. The translation students during both rounds of experiment spent less time revising the expressive text than the informative text. This might possibly be explained by the fact that all of them stated in their self-report questionnaires that the expressive text was more challenging to translate due to the stylistic devices, such as metaphors, epithets and similes, used by the author. Even though there were no time constraints imposed on participants, 
the students might have felt overwhelmed by having to translate two completely different texts at a time, and might have been therefore reluctant to continue working on a more demanding text.

Figure 2 shows the duration of the stage of end revision in percentage when each group was divided into the Thinking and Feeling type participants according to the results of the MBTI test. In the Figure, the participants with the preference for the Thinking function are marked as "Thinkers" and those with the Feeling function preference as "Feelers".

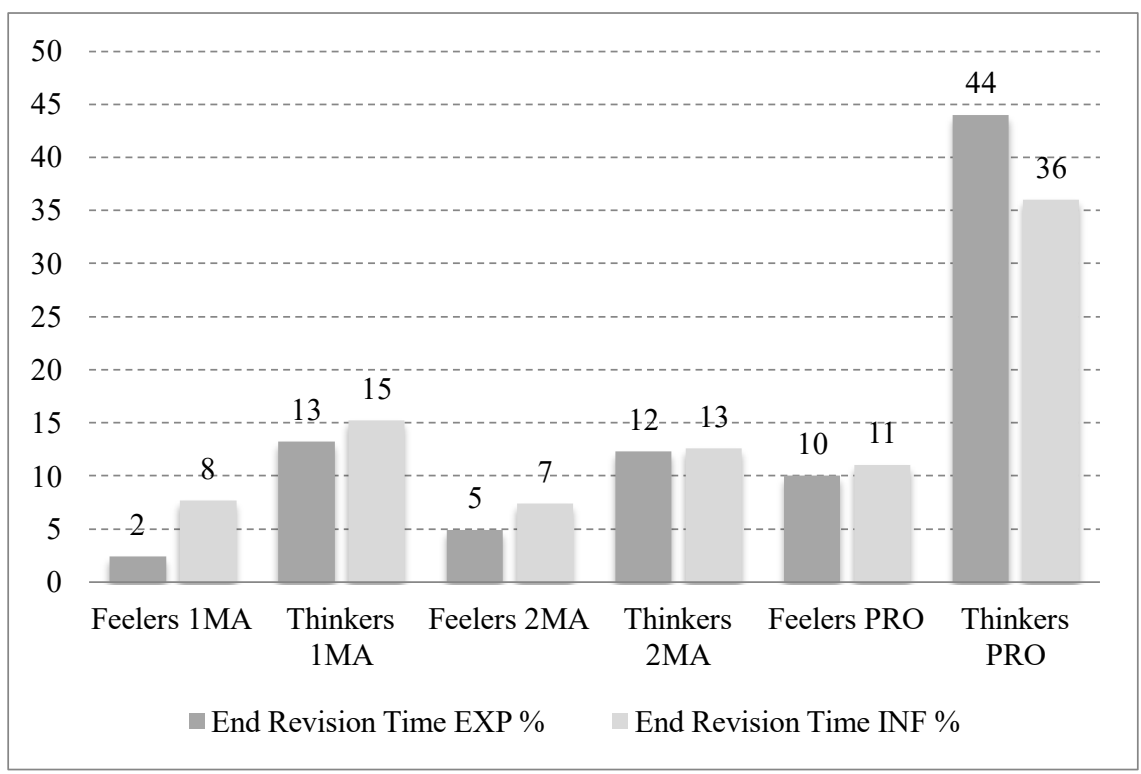

Figure 2. Mean duration of the stage of end revision: per psychological function, both texts.

In all groups, it took the Thinking type participants longer to revise their target texts than the Feeling types. However, the most considerable difference is between the Feeling and Thinking type professional translators. This might potentially indicate that with growing expertise in their field translators develop one of the two different working styles: either they draft the translations quickly and then revise the target texts extensively, or they draft and 
immediately revise their translations without the need for a long end revision stage. In the former case they show a more analytical approach to translation with their Thinking function preference, and in the latter a more subjective and evaluative approach with their Feeling function preference. Englund Dimitrova (2005) and Hansen (2013) made a similar observation concerning individual behavioural preferences of translators regardless of their level of expertise. In a similar vein, Schaeffer et al. (2019) found no effects of expertise on translators' revision behaviour.

The next temporal indicator considered for analysis was the mean duration of pauses made at the stage of end revision. As neither screen-recording nor eye-tracking was used in this study, it was methodologically impossible to trace what exactly was happening during the pauses - participants could engage in doing research, rereading the target texts and/or comparing it with the source text, thinking over the potential translation variants without putting down the interim solutions etc. However, all of these activities performed at the stage of end revision contribute to translators' final decisionmaking behaviour, which is in the centre of attention for the present study.

Figure 3 illustrates the mean pause length (in seconds) in all groups of participants and in both texts.

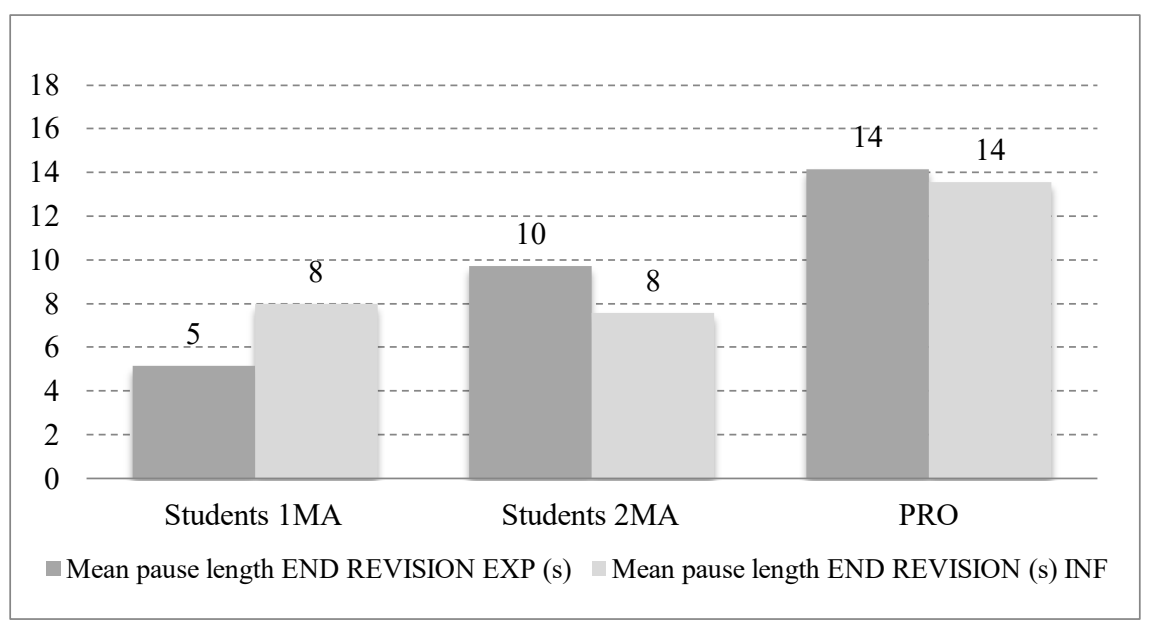

Figure 3. Mean pause length at end revision stage: all participants, both texts. 
The translation students in their first year made on average the shortest pauses at the stage of end revision. They also made slightly shorter pauses while revising the expressive text than the informative text. In their second year, the translation students showed a similar pattern as professional translators in terms of the average length of pauses. This may probably be explained by their ability to better monitor and evaluate their translation decisions in their mind as "the problem space" (Dragsted 2012: 95) in comparison with the 1MA students who only begin developing their translation competence.

Figure 4 shows that mean duration of pauses made by participants divided by the preferred psychological function while they were translating both texts.

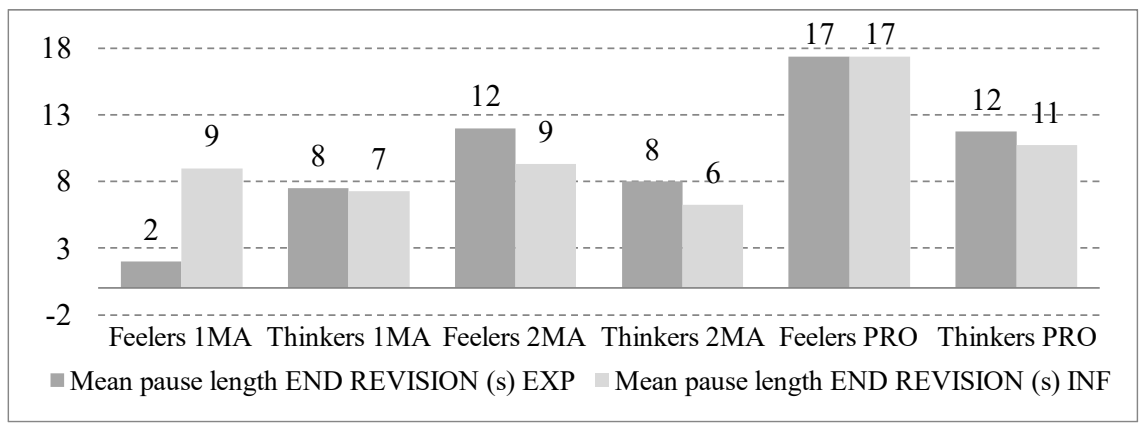

Figure 4. Mean pause length at end revision stage: per psychological function, both texts.

Dividing the participants into the Thinking and Feeling types helps to observe that 2MA students and professional translators again show similar behavioural patterns: in both groups and texts the Feeling type participants made longer pauses at the end revision stage than the Thinking type participants. Translation students in their first year did not show any considerable differences in terms of mean pause length, with the exception of those made in the expressive text. Thinking type 1MA students made longer pauses while end-revising the expressive text than their Feeling type counterparts. This can probably be explained by the fact that they also spent much less time on the stage of end revision (only $2 \%$ of the total task time) while working on the expressive text. 
Figure 5 illustrates the number of pauses made at the stage of end revision by all participants in both texts.

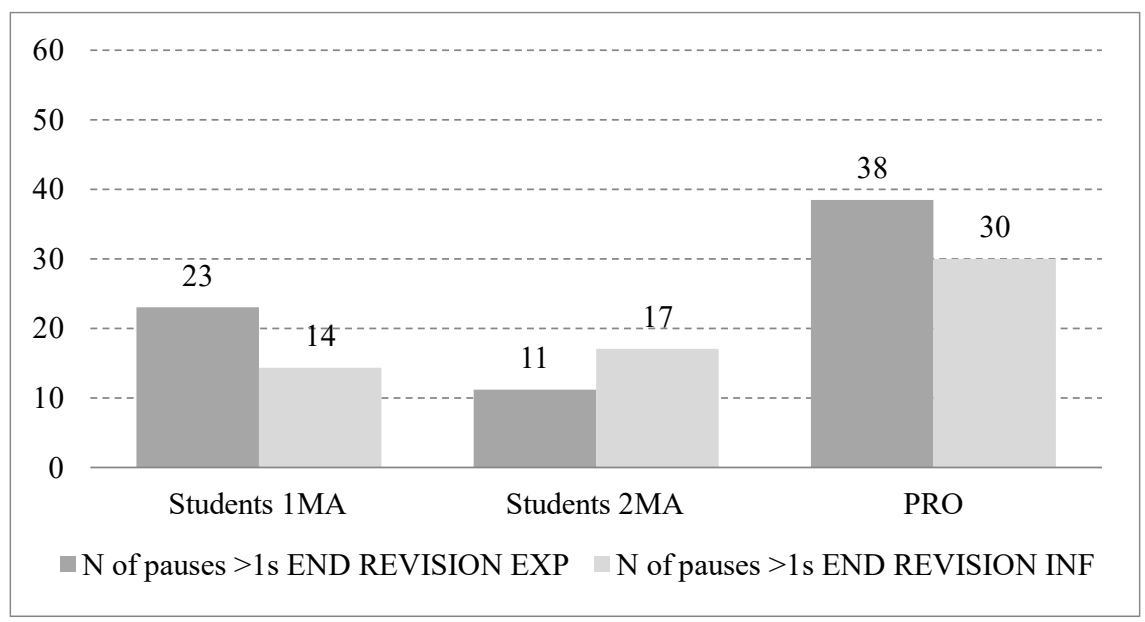

Figure 5. Mean number of pauses made at the end revision stage: all participants, both texts.

The professional translators made the largest number of pauses while endrevising both texts in comparison with translation students during both experimental rounds. The 1MA translation students made more pauses while end-revising the expressive text than they did in their second year. Thus, the first year students made more pauses while translating the expressive text, but the pauses were also shorter than those made by the same participants the following year. Notably, the 1MA translation students and professional translators made a similar number of pauses, with similar patterns in the two texts: more pauses were made in the expressive text than in the informative text. This observation is different to those made while discussing the variables of end revision time and pause length, where the patterns were similar for the groups of the 2MA translation students and professional translators. As far as the number of pauses is concerned, both the 1MA translation students and professional translators made comparatively many pauses, but in the former group the pauses were much shorter than in the latter. 
A more detailed look at the distribution of pauses is possible with Figure 6 , which shows the mean number of pauses made at the end revision stage by all participants divided per preferred psychological function.

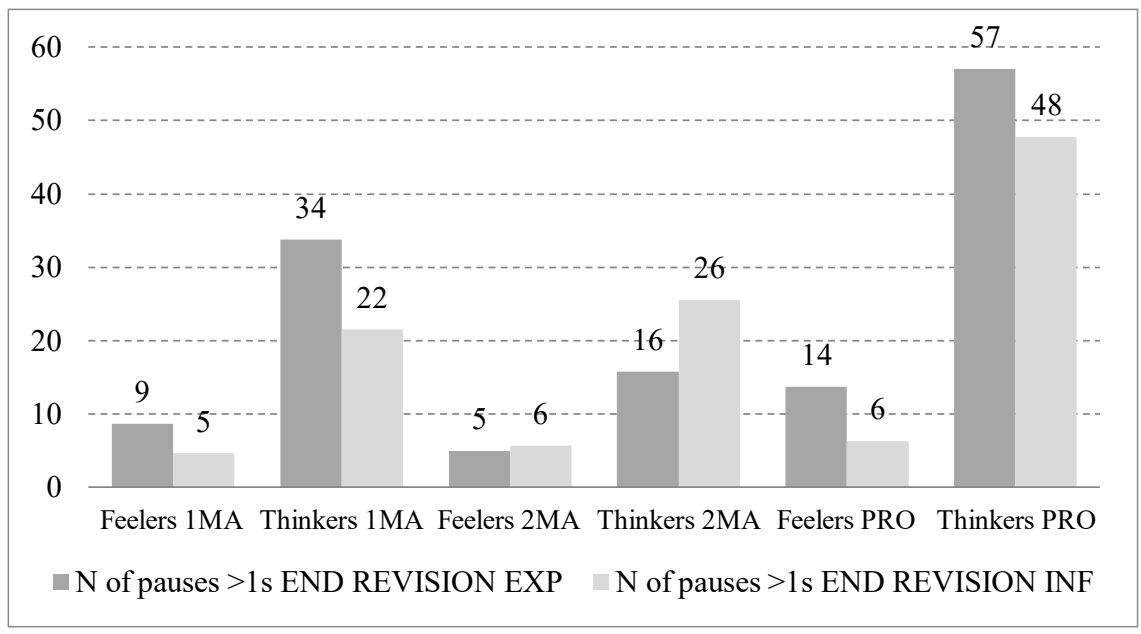

Figure 6. Mean number of pauses at the end revision stage: per psychological function, both texts.

In all groups the Feeling types participants made fewer pauses in both texts than the Thinking type participants. Thus, the Feeling types seem to have a tendency to make fewer, but longer pauses than the Thinking type translators regardless of the text type. This is in line with the description of the Feeling type decision-makers who need time to evaluate their decisions.

Another interesting observation concerns the similar behaviours of the 1MA translation students and professional translators: both Feelers and Thinkers made more pauses while end-revising the expressive text than the informative text. On the contrary, all the 2MA students made more pauses in the informative than in the expressive text. This points to the potential role of the text type: while the 2MA students by the end of their translation training programme had had extensive practice of translating different text types, including those that require a more creative approach, both the 1MA students and professional translators might have been more unfamiliar with the expressive text. However, in order to better understand the type of behaviours 
displayed by the participants, it is necessary to look and the quantitative and qualitative indicators of their decision-making styles. In other words, the variables of the number of deleted characters and the types of corrections introduced at the end revision stage will help to observe what exactly was happening between pauses at this stage of the translation process.

Figure 7 shows the mean numbers of deleted characters at the end revision stage made by all groups of participants and in both texts.

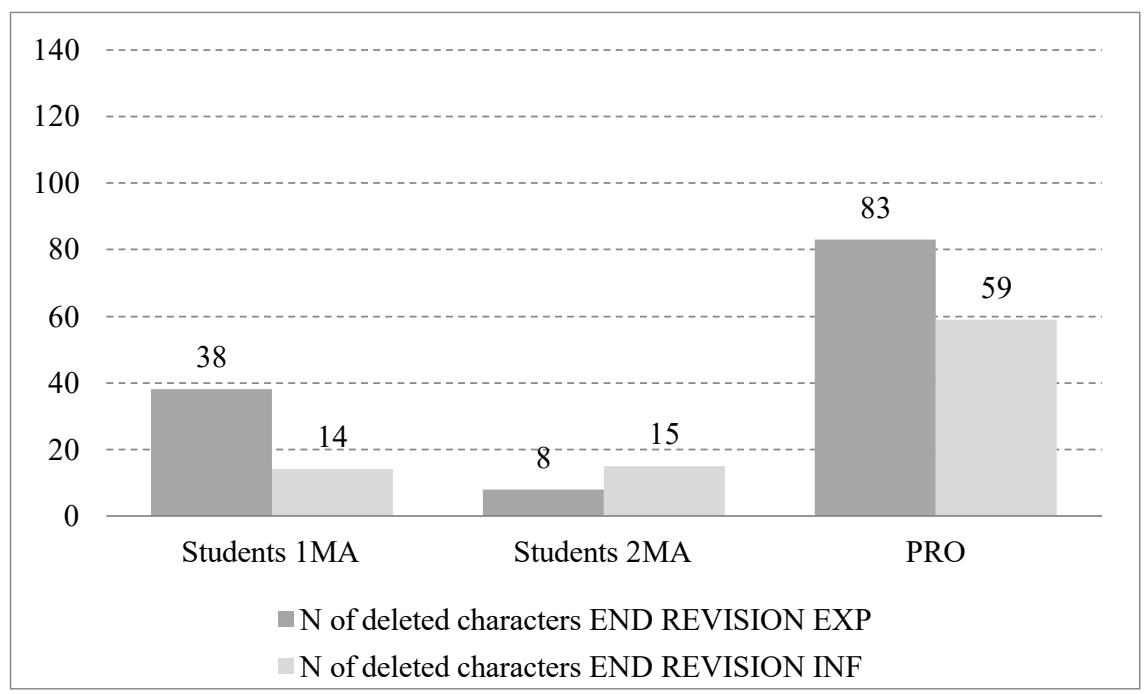

Figure 7. Mean number of deleted characters at end revision stage: all participants, both texts.

The 1MA translation students and professional translators again displayed similar behavioural patterns: both groups made more deletions in the expressive text than in the informative text in comparison to the students in their second year. Thus, not only did the two groups make more pauses in the expressive text, but also more deletions, which probably indicates that the expressive text was more challenging and new for them.

Figure 8 illustrates the mean number of deleted characters made in both texts by the participants divided according to their preferred decision-making function. 


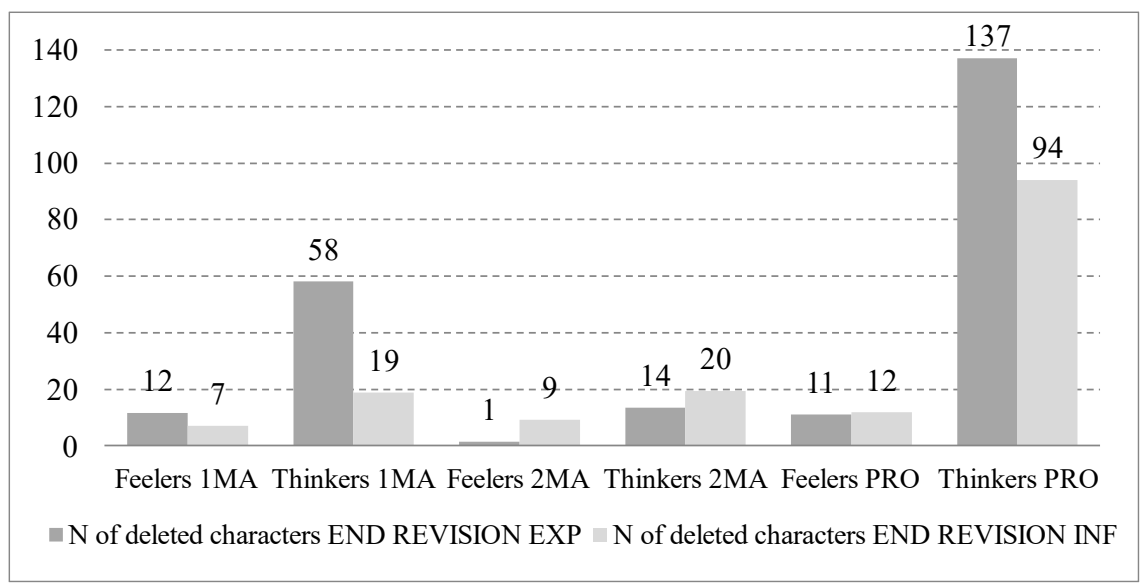

Figure 8. Mean number of deleted characters at end revision stage: per psychological function, both texts.

In all three groups of participants, those with the preference for the Thinking function introduced more deletions than those with the Feeling preference. This is another indicator of the translators' working styles: the Thinkers' end revision stage is not only longer with more and shorter pauses, but also with more characters deleted at this stage than in the case of participants with the preferred Feeling function.

In comparison to the other two groups, both types of the 2MA translation students made more deletions in the informative text than in the expressive text. Thus, the students in their second year made more, but shorter pauses, and also introduced more deletions in the informative text than in the expressive text. This may support the previously made point about the fact that students in their second year might have been more confident in translating the legal texts due to extensive practice during the two years of their translation training. The observation may also probably indicate that the students were aware of the fact that some of their initial translation solutions needed reme$\mathrm{dy}$, and were more active in introducing the necessary corrections at the stage of end revision. As regards the expressive text, they might have spent more time rereading their translations to check for any inconsistencies of style or genre, which is supported by fewer and longer pauses during the 2MA students' end revision stage in the expressive text. On the other hand, both the 
1MA students and professional translators might have not had too much practice in translating literary texts, and so they showed more active decision-making behaviours while working on the expressive text than on the informative text.

In order to better illustrate which particular solutions were revised, Figure 9 shows the mean number of "surface" and "deep" corrections (meaningnon-modifying and meaning-modifying/syntactic respectively) made by all participants in both texts. The bars with lighter colours show surface and deep revisions in the expressive texts, and those with darker colours in the informative text.

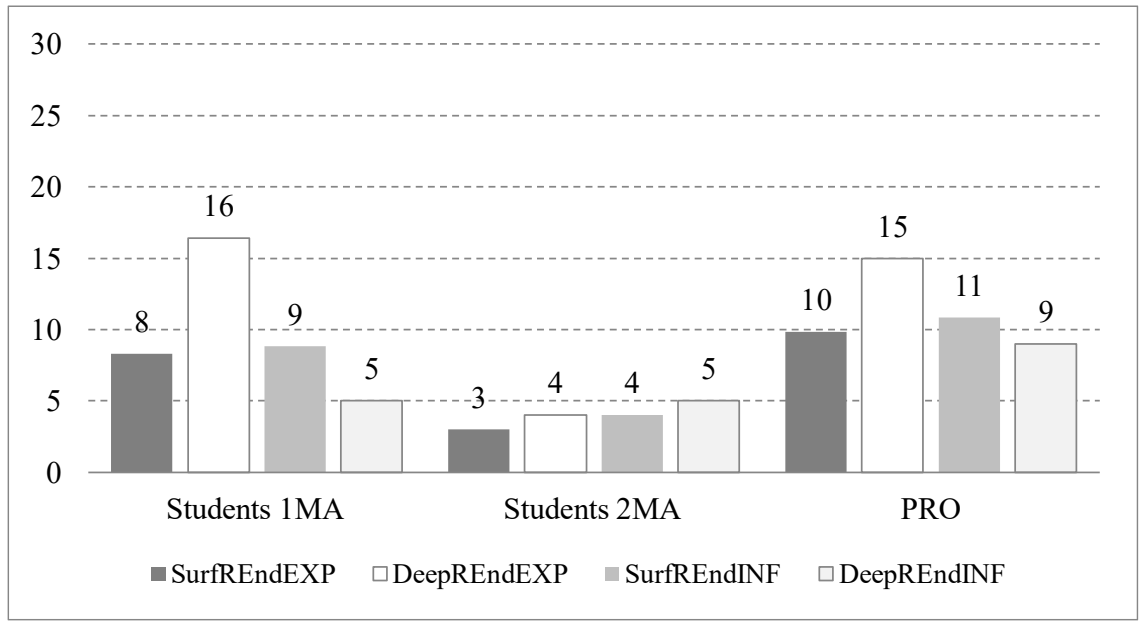

Figure 9. Mean number of surface and deep corrections: all participants, both texts.

The groups of 1MA students and professional translators again display similar behavioural patterns: more deep than surface revisions in the expressive text, and more surface than deep revisions in the informative text. The group of 2MA students made on average fewer corrections of both types in the two texts than the other two groups, with almost no differences between the text types. 
A closer look at the distribution of different types of corrections is possible with Figure 10, which shows the data in all groups divided per preferred psychological function, and in both texts.

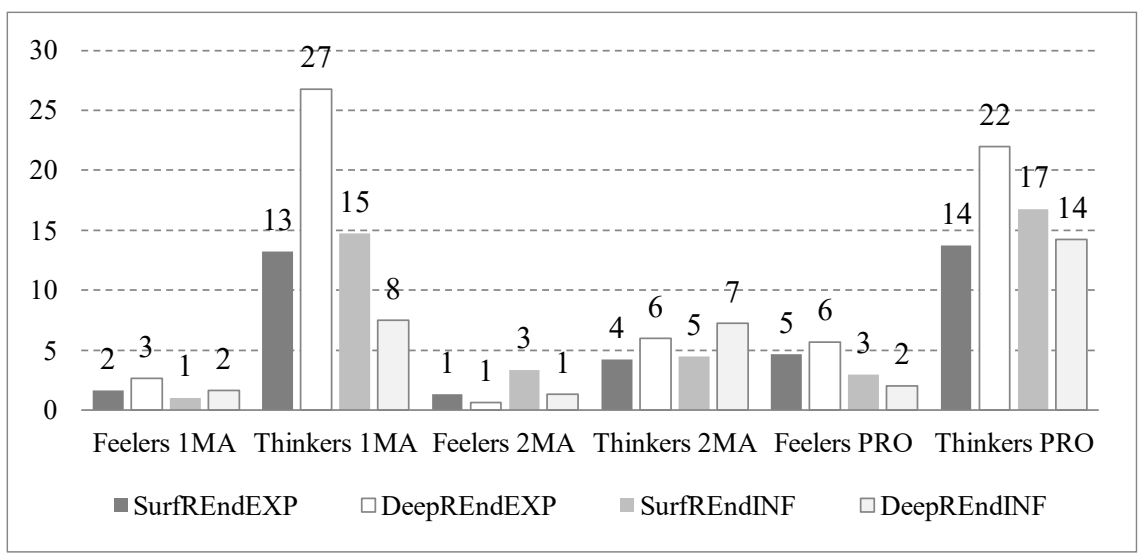

Figure 10. Mean number of surface and deep corrections: per psychological type, both texts.

The data show another evidence for the two working styles that are related to the preferred decision-making function, Thinking or Feeling. In all groups, the Thinking type participants made more of both types of corrections than the Feeling type participants. All Thinking types were particularly active while introducing "deep" corrections in the expressive text (cf. Englund Dimitrova 2005).

However, it is also possible to observe that both Thinking and Feeling type 2MA students made slightly more corrections of both types in the informative text than in the expressive text. Again, this observation may potentially hint at the role of familiarity with the text type as discussed for the previous variables.

Hence, the data presented above lead to the following conclusions related to the three hypotheses put forward in the previous sections:

Hypothesis 1. The hypothesised tendency was observed: the preferred decision-making function (Thinking or Feeling) influences such behavioural 
characteristics in the translation process as end revision time, the number and length of pauses made at the stage of end revision, the number of characters deleted at this stage, and the type of corrections made at the end revision stage. This means that the translators have two distinct decision-making styles that depend on their psychological preferences: either they have a preference for the Thinking function and therefore have a more extensive end revision stage, or they prefer the Feeling function and have a short stage of end revision, with more time and effort invested in the stage of drafting the translation (Krings [1995] 2001; Asadi \& Séguinot 2005; Dragsted 2012; Dragsted \& Carl 2013; Lehka-Paul 2018). In particular, the translators with the preference for the Thinking function tend to have longer end revision stage with more, but shorter pauses at this stage, more deleted characters and more of both "surface" and "deep" revisions, especially more "deep" corrections in the expressive text, as opposed to the translators with the Feeling function preference as regards the process of decision-making.

Hypothesis 2. The hypothesised tendency was partially observed: the preferred decision-making functions retain their influence on decision-related behavioural characteristics in the translation process as translation competence develops. The students in both years of their translation training showed similar patterns of behaviour as based on their preferred decisionmaking function. However, the students in their second year showed less activity in terms of the length and number of pauses, as well as the number of deletions and the types of corrections made in the expressive text. This may indicate that even though they considered the expressive text to be more challenging, they might have had more practice with theses types of texts than when they were first year translation students, or than the group of professional translators. Therefore, they were more active while revising their decisions in the legal text, where they were able to implement the practical skills they had gained while working with similar texts in the course of translation training. This observation poses the question of whether it is the level of text difficulty, as previously suggested by translation scholars (e.g. Dragsted 2005), or perhaps the degree of familiarity with the text type that causes changes in the translators' behaviour in the process of translation.

Hypothesis 3. The hypothesised tendency was observed: preferred decisionmaking functions are observable in the translators'decision behaviour in the translation process irrespective of expertise level. Indeed, both students and 
professional translators when divided according to the preferred decisionmaking psychological function showed similar behavioural patterns in terms of all indicators considered. Moreover, professional translators displayed even more distinct patterns than students, with the Thinking types showing the ability to clearly divide their translation process and rely on the stage of end revision for final decision-making. This is in line with Hansen (2013) whose longitudinal study showed no differences in translators' styles of behaviour in the translation process as their expertise in translation had grown.

\section{Concluding remarks and further research avenues}

Previous research into the behavioural aspects of the translation process has shown that there is a lot of individual variation in the translation process, especially at the stage of end revision characterised by final decision-making and quality control (Jakobsen 2003; Dragsted 2005). Moreover, researchers generally agree that two behavioural patterns that compose the translators' working styles can be observable: long end revision stage with a lot of target text modifications, and short end revision stage with very few target text modifications (Mossop 2007; Carl et al. 2011; Dragsted \& Carl 2013). The present study has shown that the frequently reported variations and the two "working styles" can potentially be accounted for by the translators' preferred psychological function responsible for decision-making. This is an important observation that may testify to the fact that the process of translation is a type of "cognitive behaviour" (Wilss 1996) that may be influenced by the translators' individual psychological preferences.

However, as the present study was conducted on a small data set, it is advisable that future studies of similar type should be conducted on a larger participant sample, with more experimental rounds and also with different but comparable texts. Hence, considering the methodological limitations of the present study, its findings should be treated as an inspiration for further research into the relationship between translators' psychological characteristics and their behaviour in the process of translation.

An interesting finding concerns the fact that the role of the psychological functions remains unchanged as translation competence and expertise grows, i.e. similar behavioural tendencies can be observed in translation students and professional translators. However, the data showed that the professional translators, when divided into the Thinking and Feeling types, had even more 
distinct differences in their behavioural patterns than translation students. This probably means that the decision-making styles may be rooted in the translator's personality from the very beginning of their translation practice, and become even more observable as translation competence and expertise grow (Hansen 2013). Thus, translation students need to be made aware of the existence of different working styles, and encouraged for more extensive self- and peer-observation for learning purposes. This will potentially help future translators build their professional "self-concept" (Kiraly 1995) and develop their translation routines much faster.

Despite the fact that the data showed similar tendencies in the groups of translation students and professional translators when divided according to their preferred decision-making function, professional translators overall introduced more deletions at the stage of end revision, made more and longer pauses at this stage of the translation process than translation students. This observation is in line with some earlier findings related to the differences between translation students and professional translators in terms of their revision behaviour (e.g. Carl et al. 2011), and goes contrary to some more recent studies (e.g. Schaeffer et al. 2019) in which no interactions were reported between translators' expertise level and their revision behaviour. There might be at least two potential explanations for such differences. On the one hand, the criteria used to define translation expertise are not the same in different empirical studies. On the other hand, Schaeffer et al. (2019) analysed the data collected from a large pool of participants but, importantly, there were six languages from different language families involved in the study. Hence, it might be worthwhile to further explore the influence of language relatedness (e.g. differences between revision procedures in the translation process to/from non-related languages such as Polish and English as opposed to related languages such as English and German) and script switching (e.g., such as in the pair English-Japanese as opposed to English-Polish) on the translators' revision behaviour at different translation expertise levels. In addition, it might be insightful to extend the discussion of translators' decision-making styles as related to the translators' psychological predispositions to the drafting stage as well.

To conclude, the study of the translators' decision-making styles, which combined personality psychology and translation process research, has demonstrated the psychological nature of the decision-making processes in translation. It has also provided a potential explanation for the individual var- 
iations frequently observed and reported in translation process studies, and inspired further research into the psychological aspects of translation.

\section{References}

Alamargot, D. \& L. Chanquoy. 2001. Through the models of writing. Dordrecht: Kluwer Academic Publishers.

Antunović, G. \& N. Pavlović. 2011. Moving on, moving back or changing it here and now: Self-revision in student translation processes from L2 and L3. Across Languages and Cultures 12 (2). 213-234.

Asadi, P. \& C. Séguinot. 2005. Shortcuts, strategies and general patterns in a process study of nine professionals. META: Translators' Journal 50(2). 522-547.

Briggs Myers, I. 1962. The Myers-Briggs Type Indicator: Manual. Palo Alto: Consulting Psychologists Press.

Carl, M. 2012. Translog-II: A program for recording user activity data for empirical translation process research. IJCLA 3(1). 153-162.

Carl, M., B. Dragsted \& A.L. Jakobsen. 2011. A taxonomy of human translation styles. Translation Journal 16(2). 155-168.

Chanquoy, L. 1997. Thinking skills and composing: Examples of text revision. In: J.H.M. Hamers and M. Overtoom (eds.), Inventory of European programmes for teaching thinking, 179-185. Utrecht: Sardes.

Dragsted, B. 2005. Segmentation in translation. Differences across levels of expertise and difficulty. Target 17(1). 49-70.

Dragsted, B. 2012. Indicators of difficulty in translation: Correlating product and process data. Across Languages and Cultures 13(1). 81-98.

Dragsted, B. \& M. Carl. 2013. Towards a classification of translation styles based on eye-tracking and key-logging data. Journal of Writing Research 5(1). 133-158.

Englund Dimitrova, B. 2005. Expertise and explicitation in the translation process. Amsterdam: John Benjamins.

European Master's in Translation. Competence Framework. 2017. https://ec.europa.eu/info/sites/info/files/emt_competence_fwk_2017_en_web.pdf (Date of access: 1 Dec 2019.)

Fabio A. \& D.C. Vale. 2017. On drafting and revision in translation: A corpus linguistics oriented analysis of translation process data. In: S. Hansen-Schirra, S. Neumann \& O. Čulo (eds.), Annotation, exploitation and evaluation of parallel corpora, 89-110. Berlin: Language Science Press.

Furnham, A., T. Jensen \& J. Crump. 2008. Personality, intelligence and assessment centre expert ratings. International Journal of Selection and Assessment 16(4). 356-365.

Gardner, W.L. and M.J. Martinko. 1996. Using the Myers-Briggs Type Indicator to study managers: A literature review and research agenda. Journal of Management 22(1). 45-83. 
Göpferich, S. \& R. Jääskeläinen. 2009. Process research into the development of translation competence: Where are we, and where do we need to go? Across Languages and Cultures 10(2). 169-191.

Hansen, G. 2013. Many tracks lead to the goal. A long-term study on individual translation styles. In C. Way, S. Vandepitte, R. Meylaerts \& M. Bartlomiejczyk (eds.), Tracks and treks in translation studies. Amsterdam: John Benjamins. 4962.

Higgs, M. 2001. Is there a relationship between the Myers-Briggs Type Indicator and emotional intelligence? Journal of Managerial Psychology 16(7). 509-533.

Hubscher Davidson, S. 2009. Personal diversities and diverse personalities in translation: A study of individual differences. Perspectives: Studies in Translatology 17(3). 175-192.

Hurtado Albir, A. (ed.). 2017. Researching translation competence by PACTE Group. Amsterdam: John Benjamins.

Jakobsen, A.L. 2002. Translation drafting by professional translators and translation students. In G. Hansen (ed.), Empirical translation studies. Process and product (Copenhagen Studies in Language 27), 191-204. Copenhagen: Samfundslitteratur.

Jakobsen, A.L. 2003. Effects of think aloud on translation speed, revision and segmentation. In F. Alves (ed.), Triangulating translation: Perspectives in process oriented research, 69-95. Amsterdam: John Benjamins.

Jung, C.G. [1921] 1971. Psychological types. Collected Works of Carl Gustav Jung (volume 6). Princeton, NJ: Princeton University Press.

Kiraly, D. 1995. Pathways to translation: Pedagogy and practice. Kent: The Kent State University Press.

Krings, H. [1995] 2001. Repairing texts: Empirical investigations of machine translation post-editing processes. (Translated by G.S. Koby, G.M. Shreve, K. Mischerikow, S. Litzer.) Kent: The Kent State University Press.

Lehka-Paul, O. 2018. Between translation process and product: Personality and translator's behaviour during self-revision. In S. Barschdorf \& D. Renna. (eds.), Translating boundaries: Constraints, limits, opportunities, 21-48. Stuttgart: Ibidem.

Lehka-Paul, O. \& B. Whyatt. 2016. Does personality matter in translation? Interdisciplinary research into the translation process and product. Poznań Studies in Contemporary Linguistics 52 (2). 317-349.

Maugham, W.S. 1988. Sixty-five short stories. London: Heinemann.

Mossop, B. 1982. A procedure for self-revision. Terminology Update 15(3). 6-9.

Mossop, B. 2007. Empirical studies of revision: What we know and need to know. The Journal of Specialised Translation 8. 5-20.

Muñoz Martín, R. 2014. A blurred snapshot of advances in translation process research. In R. Muñoz Martín (ed.), MonTI (Special issue 1: Minding translation), 49-85. Publicaciones de la Universidad de Alicante.

Nicholson, N.S. 2005. Personality characteristics of interpreter trainees: The MyersBriggs Type Indicator (MBTI). The Interpreters' Newsletter 13. 109-142.

O'Brien, S. 2006. Eye-tracking and translation memory matches. Perspectives: Studies in Translatology 14(3). 185-205. 
Piolat, A. 1990. Vers l'amélioration de la rédaction de texte. Apport des technologies nouvelles pour larecherche et l'apprentissage. (Synthèse pour l'Habilitation à Diriger des Recherches.) Université de Provence, Aix-en-Provence.

Reiss, K. [1971] 2000. Type, kind and individuality of text: Decision making in translation. (Translated by S. Kitron.) In L. Venuti (ed.), The translation studies reader, 160-171. London: Routledge.

Schaeffer, M., A. Tardel, S. Hofmann \& S. Hansen-Schirra. 2019. Cognitive effort and efficiency in translation revision. In E. Huertas-Barros, S. Vandepitte \& E. Iglesias-Fernández (eds.), Quality assurance and assessment practices in translation and interpreting, 226-243. Hershey: IGI Global.

Schweda Nicholson, N. 2005. Personality characteristics of interpreter trainees: The Myers-Briggs Type Indicator (MBTI). The Interpreters' Newsletter 13. 109-142.

Stilwell, N.A., M.M. Wallick, S.E. Thal \& J.A. Burleson. 2000. Myers-Briggs Type and Medical Specialty Choice: A New Look at an Old Question. Teaching and Learning in Medicine 12(1). 14-20.

Toury, G. 1995. Studying interim solutions: Possibilities and implications. In G. Toury (ed.), Descriptive translation studies and beyond, 181-193. Amsterdam: John Benjamins.

Wilss, W. 1996. Knowledge and skills in translator behaviour. Amsterdam: John Benjamins.

\section{Corresponding author:}

Olha Lehka-Paul

Adam Mickiewicz University

Wieniawskiego 1

61-712 Poznań

Poland

olehka@wa.amu.edu.pl 